\title{
The Role of Chemical Factors in the Diabetes and the Prediabetes that Leads to Polimorfe Oro -Maxilo- Facial Alterations in Malformative Syndrome
}

\begin{abstract}
IRINA ESANU ${ }^{1}$, IULIAN CONSTANTIN**, CRISTIAN CONSTANTIN BUDACU ${ }^{1 *}$, DORIANA AGOP FORNA*, CONSTANTIN MIHAI ${ }^{1}$ ${ }^{1}$ Grigore T. Popa University of Medicine and Pharmacy, Faculty of Dental Medicine, 16 Universitatii Str., 700115, lasi, Romania 2Dunarea de Jos University of Galati, Faculty of Medicine and Pharmacy, 47 Domneasca Str., 800008, Galati, Romania

There is no doubt that many psycho-emotional factors interfere with and produce changes in reproduction. Neglecting them means depriving our actions of efficiency because they will be incomplete. The adoption of the general term malformation syndrome to encompass all malformations draws attention on policy conditions set and communicate any teratologic process. Being a metabolic disease with clinical manifestations and multiple biochemical alterations, diabetes is a frightening scar of our century, considered to be the most important disease, which in itself leads to buccal-maxillo-facial polymorphic alterations. The study group consisted of 90 patients with congenital diabetes and stomatologic problems, aged between 26 and 65 years, the average age being 45 years. Distribution by gender: 60 men and30 women. Periodontal lesions are disturbing or distressing inflammation hyperplasic tissues of periodontium and quantity independence tissue affected to delineate both gingivitis and periodontitis. The most important factor in the epidemiology of the periodontal disease for prophylaxis is oral hygiene.
\end{abstract}

Keywords: psycho-emotional factors, malformations, polymorphic alterations, diabetes melitus, oral maxillofacial.

Diabetes mellitus is a current health problem with a growing incidence and prevalence, affecting increasingly younger ages. It is a chronic condition that concerns the state of nutrition of the whole organism and through the development of which disrupts the progress of the intermediate metabolism of all the food principles: carbohydrates, lipids, proteins[1-3]. The term diabetes mellitus includes a varied number of chronic diseases characterized by hyperglycemic value and the relative or absolute deficiency of insulin. Hyperglycemia is the most evident marker in the complex of biochemical markers of metabolic changes that affects the glucidic metabolism, lipidic protidic and electrolytic and may alter many of the organs and functions of the wholebody. Diagnosis of diabetes is based on clinical signs and laboratory investigations. The clinical picture is typical in about half of the cases and the main signs are polyuria, polydipsia, weight loss. Along with them, others may be present in the clinical scheme: asthenia, fatigue, decreased physical and intellectual strength, polyphagia[46]. Sometimes, the diagnosis of diabetes can be revealed by the presence of signs of infectious complications. They can drive to certainty the signs and symptoms of acute metabolic complications of diabetes plus the identification of chronic degenerative changes (Gries FA, 2003).Over time it has been used several sets of diagnostic criteria of diabetes, butnow, recognized by all international fora are the national criteria approved by the World Health Organization (WHO).

More than that, the studies published in literature showed the HbAlc determination, which is a long-term glycemic control parameter, would be a more accurate indicator of chronic exposure to hyperglycemia as compared to spot glucose dosing. Consequently, an expert group of international organizations set the $\mathrm{HbAlc}$ level of $6.5 \%$ in 2008 as the threshold from which diabetes should be diagnosed, a criterion adopted in 2010 by the American Diabetes Association[7-9].
Theories that try to explain the genesis of its chronic complications have been found to be inadequate. The disease, initially characterized by the loss of glucose homeostasis, progressively evolves and is accompanied by an increased risk of atherosclerosis. Interestingly is not the severity of these complications, especially their great variability from patient to patient, hence the hypothesis of a multifactorial production mechanism[10,11].

Diabetes mellitus is a chronic condition that concerns the nutritional status of the whole organism during which the metabolic process of all the food principles is disrupted: carbohydrates, lipids, proteins. During decompensation, the hydro electrolytic balance is totally deregulated, the $\mathrm{pH}$ of the environment internal, etc., with all their consequences on the nutrition and functional status of the organism; still remains a disease with many unclear points, both etiopathogenetically and pathophysiologically and therapeutically.

The prophylaxis of this disease is a pressing social necessity of our day. Or, knowing and fighting the causes of diabetes can lead to a decrease in the prevalence of diabetes.

The balanced maintenance of a diabetes requires profound genetic, nutritional and therapeutic metabolic knowledge.

It is important that the development of diabetes presupposes, in some cases, the existence of obesity and that sometimes a poor diet is delaying the emergence of clinical phenomena. The molecular substrate of diabetes is varied, as is also seen in human diabetes: hyperglycemia associated with reduced cellular receptors; hyperglycemia with hypoinsulinemia, hypo insulinemia following the destruction of beta-pancreatic cells[12-14].

Diabetes is determined by multiple factors involving genetic component of a more or less importance. There is unquestionable relationship between 
HLA and insulin-dependent diabetes. If the association between HLA antigens and insulin-dependent diabetes is certain, the substrate of the interaction is hypothetical. Pancreatic cell lesions can be conditioned by two factors: circulating antibodies and cytotoxic $T$ lymphocytes. Each of them can act isolated or can act together[15-17].

Diabetes mellitus, non-insulin-dependent diabetes (NIDDM) has a strong genetic component. It is known less how the genes in hereditary induce this form of diabetes, which and how many genes contribute to disease onset as well as the ways in which they can interact. Moreover, not even a gene that contributes with certainty to the occurrence of non-insulin-dependent diabetes has been identified. It is believed that type II diabetes (NIDDM) is a possible result of the interaction of different genetic factors and some environmental factors. There is undoubtedly a strong hereditary base and the key pathophysiology of this form of diabetes is whether the majority of individuals with type 2 diabetes have a small genetic defect that produces the disease predisposition, and whether this defect affects the beta cell function of the pancreas or the insulin resistance of the Langerhans isles at the level of target tissues and organs.

If the disease is polygenic, thus not having a major predisposition gene, identifying diabetic risk factors is much more difficult.Diabetes mellitus is a disorder characterized essentially by hyperglycemia and glycosuria, followed by a variety of clinical disorders. However, the two biochemical components may be caused by various factors, pancreatic lesions that induce hypoinsulinemia or hyperinsulinemia in mature diabetes, where the defect is therefore extra pancreatic.Although the two forms of diabetes have pathogenic mechanisms and different metabolic characteristics, chronic complications are common, being a major cause of morbidity and mortality.The main objective of the pharmacological and dietetic therapy currently applied to diabetic diseases is glycemic control, between this metabolic control and the degree of development of complications there is no correlation as strong as expected. For these reasons, it is necessary to validate a new therapeutic strategy, complementary to glycemic control, which could reduce the incidence and severity of chronic complications of diabetes. Studies conducted on massive groups of diabetic patients have shown that the presence and extent of retinopathy, nephropathy and neuropathy are inversely proportional to the quality of glycemic control and last for a long time.Along with genetic factors, diabetes also competes with environmental factors, which include a range of factors related to the field, such as age and gender. There are numerous data suggesting the intervention of viral infections in the occurrence of diabetes cases[18-20].

It is now admitted that the occurrence of diabetes requires three conditions: a genetic predisposition to which a stimulating factor (inadequate diet or a toxic or biological factor) acts and a particular immune response (leading to the destruction of beta-islet cells).If diabetic syndrome is such a varied multifactorial etiology, and in this sense, all authors agree with its dual origin, hereditary and gained, the mechanism of production of this syndrome is, in general, unitary.

The role of diabetes and prediabetes in the malformative syndrome

It has been noticed that diabetic mothers often give birth to abnormal babies. The most common anomalies are polidactilia, syndactilia, malformations of the brain, the heart, the eyes and the urinary system.Cardiac abnormalities are very common. Among the children operated for cardiac abnormalities have one of the parents or diabetic grandparents.It has been shown in literature that there is a high number of cases among diabetic children (4\%). After Barasew $31 \%$ and prediabetic pregnancies are aborted.

The incidence of malformed children born to diabetic mothers is very high. Generally, it is believed that $30 \%$ of unexplained congenital malformations are due to diabetes or maternal prediabetes. The pathogenic mechanism of diabetic malformations is still unknown. The first experimental investigations with antidiabetic agents have shown that they have teratogenic effect. The women who received dimetildiguanidine during pregnancy, the frequency of abortions and neonatal mortality reached $18 \%$ (Sterne). The results are not conclusive, however, because the number of observations is too low. The mortality of children born to diabetic mothers is due to congenital anomalies (Priscilla and Wite).

The same role in the malformative syndrome seems to play and the prediabetes, a notion that has occurred during the last 10 years and which concerns the period preceding the installation of pure diabetes. This condition is characterized by an intermittentimbalance in carbohydrate metabolism, because it is especially during gravity. The syndrome finds two children with malformations from 45 (4.4\%) children born to pre-diabetic mothers 5 years before the appearance of diabetes itself.Toxicity of oral antidiabetics and insulin is difficult to assess during pregnancy. It is known that a good glycemic balance is the best guarantee that pregnancy will develop normally. It is known that the incidence of fetal marrow is higher in children born to diabetic mothers.

\section{Defense mechanisms against microbial plaque}

The host's defense functions consist of removing bacteria and their products from periodontium as well as destroying any microorganism that manages to penetrate into tissues.The first level of host defense, the saliva that bubbles the oral cavity, argues the efficacy of the gingival epithelial barrier as a barrier against bacteria as well as an active participant in the inflammatory response [2123].Mechanisms of inflammatory and immune responses are relevant as well as their importance in defending the host against the bacterial plaque. The links between these host defense mechanisms are described as coordinated by soluble mediators.

\section{Experimental part}

Material and method

The study group consisted of 90 patients with congenital diabetes and stomatological problems, aged between 26 and 65 years, the average age being 45 years. Distribution by gender: 60 men and 30 women (fig.1).

\section{Results and discussions}

90 cases of diabetes, malformations and dental problems were studied.Saliva plays an important role in preventing periodontal disease, but its actions are limited to clinical crowns: those parts of the teeth and gums that are exposed to saliva. These places are part of the salivary field of the host defense, while the gingival sulcus and periodontal pockets are in the crevicular field because the host defense In these places it is mediated by crevicular fluid and inflammatory cells.A major function of saliva is to be a vehicle for swallowed bacteria and other debris 


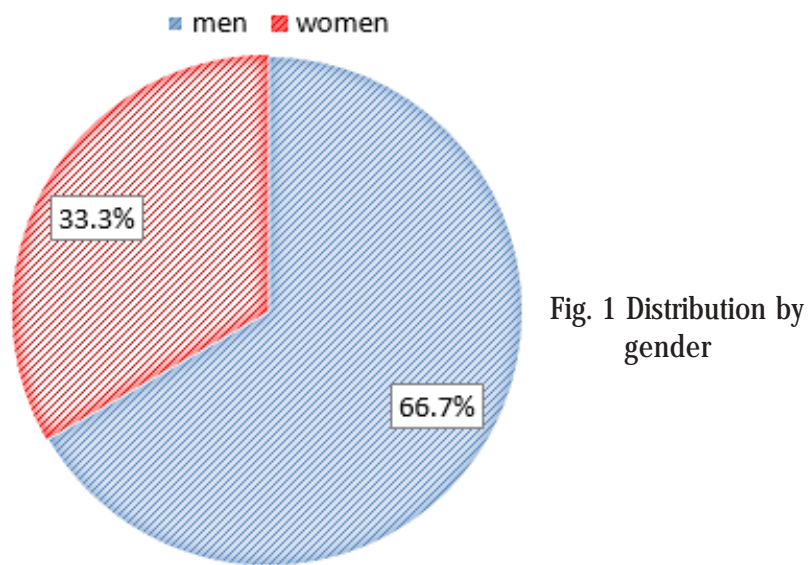

from the oral cavity. Saliva bacteria colonize teeth. It averages $10^{8}$ bacteria per $\mathrm{mL}$, their number dropping after the meal and then slowly rising again.Microorganisms multiply on the dorsal face of the tongue and the plate and are transferred into saliva by food and soft tissue movements. Then they are quickly removed by swallowing. Salivary antibacterial actions are: a vehicle for swallowed bacteria; inhibition of bacterial attachment; bacterial aggregation in saliva; bacterial killing through the peroxidase system; killing bacteria by lysozyme, lactoferrin and other factors.In addition to its antinicrobial activity, saliva, paradoxically, also contributes to plaque formation. It is a rich culture medium for those microorganisms that are adapted to live in the oral cavity and the initial colonization of the plaque. Diabetes saliva contains a variable but not increased amount of glucose, which explains the high frequency of oral cavity infections in these patients [24-27].

The specific immune system is represented in the saliva and mucosal surfaces by the secretory immune system. Unlike the humoral immune system, the secretory system produces Ac-IgA in response to mucosal surface antigens. Microorganisms in the oral cavity stimulate the system in the gut after they have been swallowed and activated lymphocytes then migrate into the salivary and secreted IgA glands.Saliva contains a non-specific antimicrobial peroxidase system consisting of salivary peroxidase enzymes, hydrogen peroxide and thiocyanate ions.The system is analogous to the myeloperoxidase system used by neutrophils to kill microorganisms. Peroxidases are synthesized by salivary glands and secreted in saliva where they bind to bacteria, and thiocyanate is secreted into saliva by duct cells. Hydrogen peroxide is continuously generated in the oral cavity at very low concentrations by bacteria, neutrophils and other host cells and is used by peroxidases to oxidize thiocyanate to hypothiocyanic acid that kills bacteria. However, although the salivary peroxidase system kills bacteria in saliva, it does not appear to inhibit platelet bacteria or periodontal pockets[28-30].

Lysozyme is another antimicrobial enzyme in saliva, and is mostly secreted by mucous salivary glands with a small contribution secreted into the cervical fluid by neutrophils.Saliva is very important in preventing excessive overgrow th and its importance is clearly demonstrated by xerostomia.The epithelial barrier function, is a major function of the oral mucosa, is to prevent the entry of bacteria and their products into tissues. In health, the junction epithelium provides sealing against bacteria around the teeth, and is permeable as a result of its adaptation to attachment, but is poorly adapted to preventing the migration of bacterial products into tissues.
With the disease, it proliferates to form the epithelium of the bag, retaining its great permeability and becoming interrupted and ulcerated. In addition to barrier function, the epithelium also has important roles in initiating and maintaining immune and inflammatory responses. Since the epithelium can induce both immune and inflammatory response, it is likely that bacteria and their plaque products will induce gingivitis by damaging the epithelium, sooner than through diffusion into connective tissue[3133].

Clinical signs of gingivitis are visible after a few days accumulation of the plaque, but the microscopic evidence of inflammation is always present, even in apparent health. Periodontitis is a classic example of chronic inflammation and those features that are not part of typical inflammatory reactions such as epithelial detachment, bag formation and tooth loss result from the particular anatomy of periodontitis.

Inflammation is the fundamental response of living tissues to aggression and develops a first line of rapid defense against lesion and infection. The functions of the inflammatory response are to reduce or eliminate the agents that cause the lesion and, if possible, to destroy them[34-36].

Since the microbial plate cannot be completely removed by host defense, the inflammatory response, which involves fluid exudation and neutrophil migration, occurs in the gum just for a short period in the early stages of the disease. Chronic migraine responses of macrophages and lymphocytes are rapidly becoming apparent, as in most chronic reactions, fluid exudation, neutrophil migration and other acute responses occur throughout the disease.

The long duration of chronic inflammation has important consequences: healing or repair attempts are prevented and a certain degree of tissue damage is inevitable. aging [47].

The dentist is best placed to detect more or less frequent oro-dental manifestations associated with general manifestations of diabetes; the lesions at the oral cavity are polymorphic and physiologically interpreted very differently. They have as substrate the degenerative arterial interest in the context of early tissue aging [37-40].

Since the earliest times (Hippocrates), the interdependence between oral pathology and general pathology has been reported.The human organism is now regarded as a unitary one and, given the increased frequency of oral manifestations during the onset and evolution of general affections, we can deduce the practical importance of oral pathological manifestations in diagnosis, prognosis and therapeutic attitude in internal diseases.

The resonance of diabetes mellitus on the oral cavity in patients with malformations is significant, affecting all components of the dental system. This system should be regarded as an integrated subsystem of the human body, any local manifestation having the potential to induce general changes, and these may also affect the homeostasis of the stomatognat system.[41-43]

There are no specific pathognomonic oral lesions that may appear in diabetes, but the stomatognat system components are affected by illnesses that have an increased incidence, a more serious development, and more common complications in patients with DM than in others [44- 46].

Modern dentistry, scientifically based on numerous clinical trials and experimental researches, highlights the 
role of systemic factors and the interrelation with the local ones, which are factors that favor the onset, form of manifestation, evolution and prognosis of periodontal diseasef (fig.2).

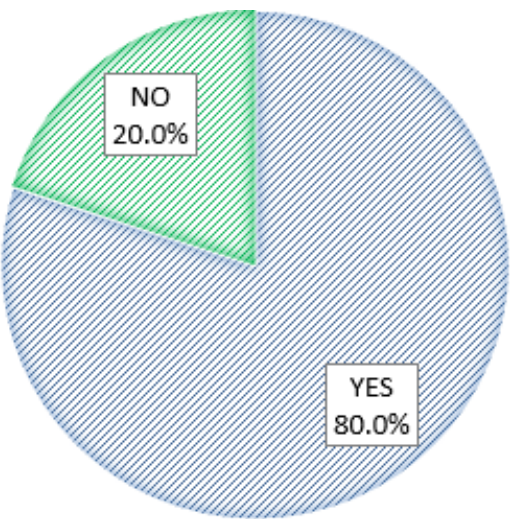

Fig.2 Presence of periodontal disease

Regarding periodontal damage, this occurred in 72 of the 90 patients who participated in the study. Of these, 31 patients (43.05\%) had chronic gingivitis, 26 chronic superficial periodontitis (36.11\%) and 15 (20.83\%) long chronic periodontitis (fig.3).

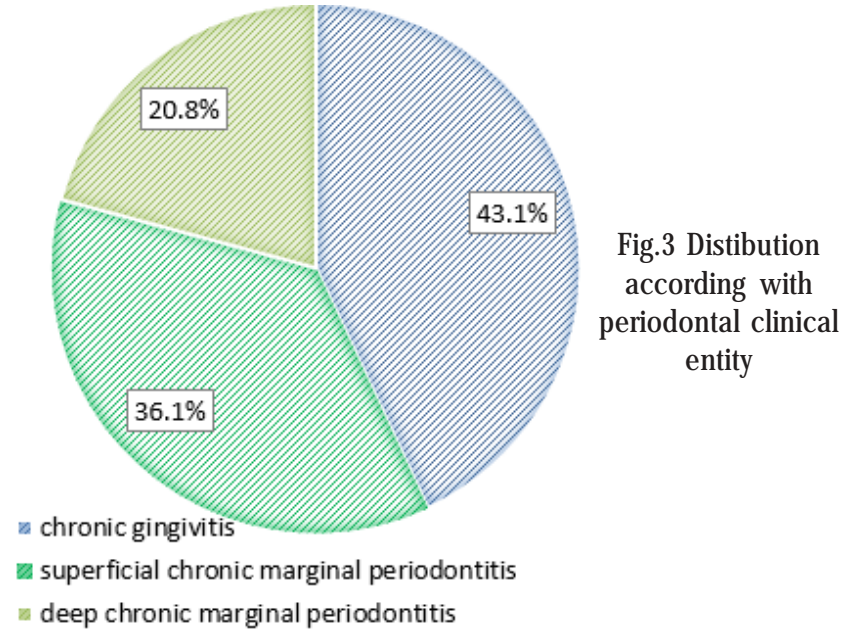

Evaluation of periodontal status was made by clinical examination and by general and local complex laboratory tests that we focus on the depth of periodontal manifestations. The clinical examination seeks to detect all signs and symptoms of early or late illness and the causal factors that may be involved in periodontal pathology. The relationship between the severity of periodontal disease and the age of diabetes, the interdependence between metabolic imbalance values and periodontal lesions was evaluated.

Most authors are of the opinion that diabetes itself is not the cause of deep gum disease and periodontitis but may favor a modified defense response from these structures to the bacterial plaque. In diabetes, inflammatory changes are more severe due to accumulation of sugar in tissues, vascular changes (microangiopathies) that aggravate dystrophic disorders in periodontium, local and general acidosis, driving to osteoporosis and progressive destruction of the alveolar bone and due to altered neutrophil functions, low resistance to infections, etc. . Also low body resistance causes periodontal complications, such as gingivalperiodontal abscesses.

Any disruption in salivary chemistry, as well as quantitative changes that occur in the context of a general condition such as diabetes, may lead to a decrease in local defense capacity against some aggressive factors primarily represented by the local ecological system. Salivary changes in diabetes mellitus can thus contribute to the induction of undesirable biological effects and the alteration of existing homeostasis.

Decreased salivary flow is more important in diabetic patients who have a history of multiple infections. These disorders entail the salivary flow dynamics and other injuries such as fissure lips, dry jugular mucosa, red, fissure, bulky tongue, and dry mouth sensation causing great discomfort, and is characteristic of insufficiently controlled diabetes, where glycolysis hemoglobin exceeds $13 \%$. Within the multifactorial etiology of inflammatory lesions of the oral mucosa and odonto-periodontal lesions the microbial factor intervenes quantitatively and qualitatively even under the conditions of a modified terrain. Oral fluid rich in glucose and a low leakage rate multiplier provides ideal conditions for microbial species aggressive, high antibacterial activity is considered by most specialists as the main cause of periodontal dental pathology.

The poor conditions of the oral environment favors microbial imbalances, and these in turn influence the changes in salivary ph occurring mainly in an uncontrolled diabetes mellitus.

The most important factor in the epidemiology of periodontal disease from the point of view of prophylaxis is dental hygiene. In the absence of this or under unsatisfactory hygiene-dental-dental conditions, the dental plaque is deposited and maintained on the surface structures of the marginal periodontium, the inflammatory disease installs and, in the absence of antimicrobial treatment, evaluates progressively through damage and deep, supporting structures, to the loss of teeth.

An overwhelming importance of the status of the oral cavity, and of the results of any dental treatment, has the status of oral hygiene. The more it is involved in the oral health of patients with diabetes, as they present poor conditions of infection protection and an environment favorable to microbial imbalances (salivary viscosity, ph, enzymes, salivary flow, electrolytes), all of which being influenced by biological constants indicating a precarious metabolic balance. Malformed patient can be guided and helped to maintain a healthy oral hygiene. Functional or developmental malformations cause developmental disabilities.

Functional or evolutional effects include metabolic defects, sensory problems and nervous system problems.

Congenital malformations of function or evolutionare related to a problem with how it works a component or a body. These problems can include: problems with the nervous system- these include disabling intellectual development, behavioral disorders, speech or language difficulties, seizures and problems in moving ( Down syndrome, Prader-Willi syndrome and fragile $X$ syndrome); sensory malformations- hearing loss, visual problems, etc.; metabolic disorders - problems withcertain chemical reactions in the body, such as diseases that limit the body's ability to remove toxins - or harmful chemicals (examples phenyl ketonuria); degenerative ulcers- diseases that may not necessarily be apparent at birth, but are constantly affecting organism, such as muscular dystrophy.

\section{Conclusions}

The congenital abnormalities may be genetic in origin, or environmental infectious, although in most cases it is difficult to identify their etiology.

The oral cavity hygiene status is a decisive factor in any prosthetic treatment, especially in patients with diabetes that have a low body resistance. 


\section{References}

1. ${ }^{* * *}$ American Diabetes Association Position Statement: Standards of medical care in diabetes. Diabetes Care 2005; 28(suppl.1):S4-S36. 2.ARMSTRONG DG, LAVERY LA, WU S, BOULTON AJM. Evaluation of removable and irremovable cast walkers in the healing of diabetic foot wounds: A randomized controlled trial. Diabetes Care 2005;28(3):551-554.

3.ARMSTRONG DG, LAVERY LA. Clinical Care of the Diabetic Foot. American Diabetes Association 2010;50-59.

4.AYUSO VELOSCO R., TORRES AGUIRRE A. - Esophageal atresia in the Goldenhar syndrome. Cir Pediatr., 2010, Jan; 23: 65-7.

5.BEMBEA M., COVIC M., MACOVEI M., JURCA C. Malformatiile congenitale izolate. În: Editor Covic M. Genetica medicala. Iasi: Polirom, 2011, p. 487-492.

6.CANNIZZARO C., BOGLIONE M. - Analysis of clinical-surgical course of neonates with long-gap esophageal atresia during their spontaneous growth.Cir Pediatr., 2009, Oct: 22(4) : 181-5.

7.CHAN JCN, MALIK V, JIA W, et al. Diabetes in Asia: epidemiology, risk factors, and pathophysiology, JAMA 2009;301:2129-2140.

8.CLEMENT S, BRAITHWAITE SS, MAGEE MM, et al. Management of diabetes and hyperglycemia in hospitals. Diabetes Care 2004;27:553591.

9.COURSIN DB, CONNERY LE, KETZLER JT: Perioperative diabetic and hyperglycemic management issues. Crit Car Med 2004;32 (suppl):S116-S125.

10.DAS UN. Is insulin an endogenous cardioprotector? Crit Care 2002;6:389-393.

11.MELIDONIS A, STEFANIDIS A, TOURNIS S, et al. The role of strict metabolic control by insulin infusion on fibrinolytic profile during an acute coronary event in diabetic patients. Clin Cardiol 2000;23:160164.

12.NANU D., MARINESCU B., MATEI D., ISOPESCU F., Esentialul în obstetrica, Ed. Medicala Amaltea Bucuresti, 2008.

13.OSTER M.E., LEE K.A., HONEIN M.A. et al. Temporal trends in survival among infants with critical congenital heart defects. În: Pediatrics, 2013, 131(5): 1502-8.

14.PANZARU M. et al. Benefits of cytogenetic testing in diagnosis of plurimalformative syndromes with congenital heart defects. În: Revista Romana de Medicina de Laborator, Vol. 20, nr. 3/4, Septembrie 2012, p. 265- 272.

15.PAPILIAN V. - Anatomia omului vol. II, Editia a XI-a , Ed. BIC ALL, 2006.

16.PETCU S. - Radiologie @i imagisticã pediatricã, Ed. Medicala, 2006. 17.PIERPOINT M.E., BASSON C.T., BENSON D.W. Jr et al. Genetic basis for congenital heart defects: current knowledge: a scientific statement from the American Heart Association Congenital Cardiac Defects Committee, council on cardiovascular disease in the Young: endorsed by the American Academy of Pediatrics. Circulation 2007, 115(23): 3015-3038.

18.SADLER T.W., LANGMAN. - Embriologie Medicalã, Editia a X-a, Ed. Medicalã Callisto Bucuresti, 2008.

19.VERESIU AI, Piciorul Diabetic, în Complicaiile cronice ale diabetului zaharat, sub red. Popa Amorin Remus, FarmaMedia, Targu Mures 2008;405-434.

20.VILLELA RODRIGUEZ J ., SALINES LOPEZ M.P. - Medical-surgical course of neonates with gastroschisis according to time, abdominal closure method and intestinal involvement. Cir Pediatr, 2009, Oct;22(4):217-22.

21.ZARABO E., BLESA SANCHES E. - Digestive malformations and their associations to syndrome condition and genetic defects. Cir Pediatr, 2010, J an;23 (1):46-52.

22.NICULESCU,O.,NICA,P., GURLUI,S.,et al., Experimental investigations of polymer plasma laser ablation, Mat. Plast., 46, no. 3 , 2009, p.336-338
23. VASLUIANU, E., POPESCU,V., GRIGORIU,A., et al., Comparative study concening the FIR Analysis and the performances of chitosan based wrinkle-proofing agents, Rev. Chim. (Bucharest), 64, no. 10, 2013, p.1104-1115

24. NASH,D.,RUOTOISTENMAKI,J ., ARGENTIERI,A.et al.,Profil of the oral healhcare team in countries with emerging economies,Conference Global Congress on Dental Education location,Dublin,Ireland, European J ournal of Dental Education,12((1), 2008, pg.111-119

25. POPESCU,V., VASLUIANU,E., FORNA,N.C., et al., Comparative study of the FTIR Analysis and the peformances of N,N,N-trimethyl chitosan as wrinke-poofing agent, Rev. Chim. (Bucharest), 64, no. 11, 2013, p.1284-1294

26.CIURCANU, O.E ,STEFANESCU, O., SCUTARIU, M.M., STELEA, C.G., Importance of the Chemistry of Local Anesthetic in Modulation of Cardio-vascular Response, Rev. Chim. (Bucharest), 67 no. 3, 2016, p. 566-569

27. SCUTARIU, MM , SALAMASTRAKIS, I, STAN CI, NEDELCU, AH. GAVRIL, LC ,COSTEA, CF, DUMITRESCU, AM, SAVA A, SAPTE, E. Histopathological consequences of hyperzincemia on rat teeth. Experimental study. Romanian Journal of Morphology and EmbryologyVolume: 57 Issue: 3 Pages: 1057-1061 , 2016

28. BOTNARIU,G., FORNA, N., POPA,A., et al., Correlation of glycemic control parameers in non-diabetic pesons with cardiovascular risk scores-results from a cross-sectional study, 8(1),2017, pg.108-110

29. IFTENI,G., APOSTU,A., TANCULESCU,O., Dental occlusion and the importance of is proper investigation-partll, Romanian Journal of Oral Rehabilitation, 8(4),2016,pg.17-22

30. JUMANCA, D., GALUSCAN,A., PODARIU,A.C., et al.,Antiinflammatory action of toothpastes conaining betulin nanocapsules,Rev. Chim.(Bucharest), 65, no. 12, 2014, p.1473-1476

31. BALAN, G., GRIGORE, C.A., BUDACU,C.C., et al., Antisepsis, Desinfection Sterilization -mehods used in dentistry, Rev. Chim. (Bucharest), 68, no.1, 2017, p.186-191

32.ZEGAN, G., DASCALU, C.G., MAVRU, R.B., Cephalometric, features of Class III malocclusion, Medical-surgical journal,119(4), ,2015, 11531160;

32.ANCUTA ,C., POMIRLEANU, C., IORDACHE,C., et al., Serum lipid profile in diffuse versus limited systemic sclerosis data from the SASS cohort, Rev. Chim. (Bucharest), 69, no. 2, 2018, p.403-406

33. BUDACU, C.C., CIORANU,S.V.,CHISCOP, I.,e al., Glucocoricoids and postoperative disease in oral-maxillofacial surgery, Rev. Chim. (Bucharest), 68, no. 11, 2017, p.2716-2719

34.NEMTOI, A., DANILA ,V., DRAGAN, E., et al., The effecs of insulin and strontium ranelate on guided bone regeration in diabetic rats, Rev. Chim. (Bucharest), 68, no. 4, 2017, p.693-697

35.ANCUTA,C., POMARLEANU,C., IORDACHE C., Periodontal disease and lipid profile in systemic sclerosis: an EUSTAR Cohot Expeience, Rev. Chim. (Bucharest), 68, no. 4, 2017, p.890-893

36.IORDACHE,C.,GHIORGE,C.A.,ANTOHEM.E., etal., Temporomandibular joint involvement in rheumatoid arthritis and ankylosing spondylitis:a cross-sectional study, 994), 2017, pg.40-46

37. MURARIU,A., PRICOP M., BOBU,L., et. al., Ethics dimensions in dentistry, Romanian Journal of Oral Rehabiliation,8(1), 2016,pg.65-71

38.POPA, C., STELEA C.G., FILIOREANU,A.M., et al., PCR Analysis of the Herpesviruses presence in crevicular fluid in HIV-positive patients, Rev. Chim. (Bucharest), 68, no. 11, 2017, p. 2672-2675

39.FORNA AGOP ,D., POPESCU, E., COSTAN V., V., et al.,Conventional maxillary reconstruction using service obturators, Romanian Journal of Oral rehabilitation,(8),3,2016, pg.32-39

40.COSTACHE, I.I., COSTEA .C.F, DANCIU,M., COSTAN, V.V., AURSULESEI,V., DUMITRESCU,G.F., TURLIUC, M.D,SAVA ,A., Amyloidosis-a rare cause of refractory heart failure in a young female, Rom J Morphol Embryol, 2017,58(1),201-2016

41.DASCALU, C.G., CARAUSU, E.M., MANUC, D., Methods for Data Selection in Medical Databases: The Binary Logistic Regression Relations with the Calculated Risks, Proceedings of world academy of science, engineering and technology, VOL 28 Book 
Series: Proceedings of World Academy of Science Engineering and Technology Volume: 28 Pages: 278-+Published: 2008

42.BRANISTEANU,D.E.,IANOSI,S.L.,DIMITRIU,A., et al., Drug-induced Rowell syndrome, a rare and dufficult to manage disease:A case report, Experimental and therapeutic medicine,15(1), 2018,p.785 43. DUCEAC, LD, STAFIE, L, VALEANU, IP, MITREA, G, BACIU, G, BANU, EA, ROMILA, L, LUCA, AC. Sepsis in paediatrics - a special form of infection associated to medical assistance. INTERNATIONAL J OURNAL OF MEDICAL DENTISTRY, 2018, 22(3): 229-235.

44. LUCA, A.C., DUCEAC, L.D., MITREA, G., CIUHODARU, M.I., ICHIM, D.L., BACIU, G., BANU, E.A., IORDACHE, A.C., Antibiotic Encapsulated Nanomaterials with Application in Medical Area., Mat. Plast., 55, no.4, 2018, p.552-554.
45. RAFTU, G., MITREA, G., MACOVEI, LA., NECHITA, A., Chemical Additives from the Composition of Plastic Products and Other Materials in Establishing Diagnosis for Alergy Disease. Mat. Plast., 55, no.4, 2018, p.609-612

46.EARAR, K., ANTONIAC, V.I., BACIU, S., et al, Etching treatment effect on surface morphology of dental structures, Rev. Chim. (Bucharest), 68, no. 11,2017, p.2700

47.SCUTARIU,M.M., CIURCANU,O.E., FORNA AGOP, D. Et al. , Importance of dental maxillofacial aesthetic in dental therapy, Medicalsurgical journal, revista medico-chirurgicala, 120(4), 2016, p.926

Manuscript received: 16.10 .2018 